\title{
A HistóRIa dA SÚMULA 331 DO TRIBUNAL SUPERIOR DO TRABALHO: A ALTERAÇÃO NA FORMA DE COMPREENDER A TERCEIRIZAÇÃO ${ }^{1}$
}

\author{
Magda Barros Biavaschi ${ }^{2}$ \\ e Alisson Droppa ${ }^{3}$
}

\begin{abstract}
ReSUMO
0 texto, fundamentado em pesquisa realizada no Centro de Estudos Sindicais e de Economia do Trabalho do Instituto de Economia da UNICAMP, CESIT/ IE/UNICAMP, analisa o processo de alteração do entendimento do Tribunal Superior do Trabalho, TST, quanto à terceirização que se expressou, em 1993, na revisão do Enunciado 256 pela Súmula 331, revisitada em 2000 para estender a responsabilidade subsidiária aos Entes Públicos que contratam terceiras. Para tanto, utilizaram-se: documentos e entrevistas, fontes que ofereceram elementos
\end{abstract}

\footnotetext{
${ }^{1} 0$ presente texto é baseado nos resultados apresentados no Relatório Cientifico Final da Pesquisa "A Terceirização e a Justiça do Trabalho", financiada pela Fundação de Amparo a Pesquisa do Estado de São Paulo-FAPESP. Disponível em: <http://www.revistas.unifacs.br/ index.php/redu/article/view/918/669>.

${ }^{2}$ Desembargadora Aposentada do TRT4, Doutora em Economia Social e do Trabalho pelo Instituto de Economia da Unicamp, IE/UNICAMP; Pós-doutora em Economia Social e do Trabalho pelo IE/UNICAMP; pesquisadora voluntária do CESIT/IE/UNICAMP; Presidente do FORUM NACIONAL PERMANENTE EM DEFESA DA MEMÓRIA DA JUSTIÇA DO TRABALHO, período 2007-2010. End. Eletrônico magdabia@terra.com.br

3 Doutorando em História Social do Trabalho, Mestre em Estudos Históricos Latino Americano. End. Eletrônico: alissondroppa@yahoo.com.br
} 
fundamentais à análise do papel da Justiça do Trabalho diante dessa forma de contratar e à discussão sobre seu potencial regulador das relações de trabalho.

Palavras-chave: Terceirização. Justiça do trabalho. Responsabilidade solidária. Responsabilidade subsidiária.

\title{
THE STORY OF SUMMARY 331 OF THE SUPERIOR LABOR COURT: THE CHANGE IN THEWAY OF UNDERSTANDING THE OUTSOURCING
}

\begin{abstract}
This text, based on a research carried out at the Center for the Study of Trade Union and Labor Economics at the Economics Institute of UNICAMP, CESIT/ UNICAMP, examines the process of changing in the understanding of outsourcing by the Superior Labor Court, expressed in 1993 in the revision of Statement 256 and Summary 331, revisited in 2000 to extend subsidiary liability to public entities that hire the third parties. Thus, we used: documents and interviews, sources that provided key elements for the analysis of the Labor Court role on this form of contract, as well as for the discussion about the potential this Institution has to regulate labor relations.
\end{abstract}

Keywords: Outsourcing. Labor court. Joint liability. Subsidiary liability.

\section{INTRODUÇÃO}

terceirização é uma das formas de contratar que mais avançou no Brasil
nos anos 1990, sendo, hoje, prática corrente em quase todos os segmentos
econômicos das esferas pública e privada, podendo expressar tanto um fenômeno interno quanto externo ao contrato de trabalho (VIANA, 2006). É vista como estratégia das empresas para reduzir custos, partilhar riscos e aumentar a flexibilidade organizacional (KREIN, 2007), passou a ganhar maior dimensão no País quando o movimento mais geral do capitalismo pressionou no sentido da liberalização dos mercados, impactando o regime de contratação da mão-de-obra.

Muitos têm sido os debates sobre essa forma de contratar, focando-a no cenário das transformações que se têm operado no mundo do trabalho, sobretudo a partir da década de 1990. Estudos na área econômica, por exemplo, apontam para crescente utilização de terceiras (POCHMAN, 2008). Evidencia-se, no entanto, uma lacuna nos estudos sobre o papel da Justiça do Trabalho diante do fenômeno 
da terceirização a qual a pesquisa que fundamenta este texto buscou suprir. Para tanto, como fonte primária prevalente, fez uso de processos ajuizados perante algumas Juntas de Conciliação e Julgamento do País, hoje Varas do Trabalho, entre 1985 e 2000, período delimitado pelo Enunciado 256, de 1986, substituído pelo TST em 1993 pela Súmula 331, alterada em 2000. Em meio a esses estudos, a pesquisa acabou se deparando com uma dinâmica específica que redundou na alteração do entendimento sumulado, foco deste texto.

No Brasil, as controvérsias e os conflitos individuais e coletivos decorrentes das relações de trabalho são julgados pelos Tribunais e Juízes do Trabalho. Cabe ao TST, precipuamente, uniformizar a jurisprudência. Daí as Orientações Jurisprudenciais e as Súmulas que, conquanto não tenham força vinculante, acabam por interferir e, até, de certa forma, por moldar uma linha prevalente nas decisões judiciais. Por outro lado, distintamente de outros países da América Latina, não há no Brasil lei específica regulando a terceirização (BALTAR, 2009) ${ }^{4}$. Foi no vácuo da lei que o TST normatizou sobre essa forma de contratar; inicialmente, coibindo-a (Enunciado 256); mais tarde, legitimando-a em relação às atividades não essenciais ao empreendimento econômico, definindo como subsidiária ${ }^{5}$ a responsabilidade da tomadora (Súmula 331); em 2000, estendendo essa responsabilidade aos Entes Públicos que contratam terceiras.

Este artigo discute o processo de alteração do entendimento do Judiciário do Trabalho brasileiro relativamente aos limites da terceirização e à responsabilização da tomadora dos serviços, assinalando certos aspectos desse processo e sua dinâmica no âmbito do TST. Não deixa de referir, porém, recente decisão do Supremo Tribunal Federal, STF, na ADC16 que acaba por desobrigar os Entes Públicos quanto ao inadimplemento trabalhista das terceiras, sinalizando, talvez, certa mudança de rumos. Para tanto, utiliza como fonte historiográfica as discussões que se deram no âmbito do TST entre seus Ministros e entrevistas com os principais atores que participaram da formulação do novo entendimento ${ }^{6}$.

\footnotetext{
${ }^{4}$ Ver: FALVO, Josiane Fachini. Balanço da regulamentação da terceirização do trabalho em países selecionados da América Latina. Revista da ABET, Campinas, v. 8, 2010.

${ }^{5}$ No subitem a seguir se buscará explicitar o que significa, juridicamente, a responsabilidade subsidiária e qual a diferença fundamental entre ela e o instituto da responsabilidade solidária. ${ }^{6}$ As fontes usadas na pesquisa estão indicadas no Relatório Científico aprovado pela FAPESP, disponível no CESIT/IE/UNICAMP e no Memorial/RS. As entrevistas integram a pesquisa, podendo ser consultadas no mesmo local. Quanto ao tema da Súmula 331, coube ao pesquisador Jorge Marques esmiuçá-lo.
} 
Discutir essa dinâmica é importante para se compreender o significado da resposta que a Justiça do Trabalho acabou dando à questão, bem como a força dos entendimentos sumulados pelo TST não apenas em relação aos magistrados dos graus inferiores de jurisdição, mas aos demais atores, como partes e advogados. Para estudar essa resposta ao fenômeno e analisar como foi sendo alterada a partir de certa correlação de forças, em determinado momento histórico, relacionando fatos, argumentos e forças em disputa de forma contextualizada, o texto parte da compreensão de que o Estado (POULANTZAS, 1990) e o Direito são uma relação (BIAVASCHI, 2007).

Com tais objetivos, inicia explicitando o significado de alguns institutos. A seguir, esclarece o sentido dos entendimentos do Enunciado 256 e da Súmula 331 do TST. Depois, aborda as circunstâncias que provocaram o ajuizamento do Inquérito Civil Público - ICP pela Procuradoria Geral da Justiça do Trabalho, tecendo considerações sobre: as demandas encaminhadas ao então Subprocurador objetivando o cancelamento do Enunciado 256; a proposta de redação substitutiva encaminhada ao TST; a redação aprovada pelo Pleno do TST. Ainda nesse item faz referência a recente entendimento adotado pelo STF no julgamento de Ação Declaratória de Constitucionalidade - ADC. Por fim, as considerações finais.

\section{ESPECIFICANDO ALGUNS CONCEITOS}

Estado, Direito e Terceirização são compreendidos de formas distintas por diversos autores. Conceituá-los não é tarefa simples.

Quanto ao Estado, o texto adota a teoria relacional do poder (POULANTZAS, 1990): o Estado é uma relação. Isto é, a condensação material e específica de uma relação de forças entre classes e frações de classes. Como o lugar de cada classe, ou do poder que detém, é delimitado pelo lugar das demais classes, esse poder não é uma qualidade a ela imanente; depende e provém de um sistema relacional de lugares materiais ocupados pelos agentes. 0 poder político de uma classe e a capacidade de tornar concretos seus interesses dependerá não somente de seu lugar de classe em relação às outras classes, mas, também, de sua posição estratégica relativamente a elas (BALTAR; BIAVACHI, 2009).

0 Direito é produto cultural (GRAU, 2002). Encontrando-se no interior da estrutura social antes de ser posto pelo Estado, não pode ser entendido apenas como produto das relações econômicas, externo a elas, como ideologia ou, ainda, apenas como expressão da vontade das classes dominantes, como instrumento 
de dominação. Sendo nível do todo social complexo - a estrutura social - nela se compõe, resultando da sua própria interação com os demais níveis desse todo. Quanto ao Direito do Trabalho, compreendido como movimento histórico, se o toma como uma relação (NEUMANN, 1983); uma relação entre empregador e trabalhador: este a vender sua força de trabalho àquele, detentor dos meios de produção, recebendo em troca o salário, único bem a compor seu patrimônio. É, assim, estabelecida uma relação não apenas obrigatória, mas de poder.

Quanto à terceirização, uma das dificuldades de conceituá-la reside nas distintas formas por meio das quais se vem apresentando no mundo do trabalho, bem como na multiplicidade de conceitos que lhes são atribuídos por autores de diversas áreas do conhecimento. Com contornos variados e, por vezes, de forma simulada, pode ser identificada, dentre outras formas:

[...] na contratação de redes de fornecedores com produção independente; na contratação de empresas especializadas de prestação de serviços de apoio; na alocação de trabalho temporário por meio de agências de emprego; na contratação de pessoas jurídicas ou de "autônomos" para atividades essenciais; nos trabalhos a domicílio; pela via das cooperativas de trabalho; ou, ainda, mediante deslocamento de parte da produção ou de setores desta para ex-empregados. Nessa dinâmica, chega-se a presenciar o fenômeno da terceirização da terceirização, quando uma empresa terceirizada subcontrata outras, e o da quarteirização, com a contratação de uma empresa com função específica de gerir contratos com as terceiras e os contratos de facção e os de parceria (KREIN, 2007).

Por vezes, certos mecanismos jurídicos ocultam a figura do real empregador dificultando a definição dos verdadeiros pólos da relação de trabalho. Daí a importância de um conceito amplo que dê conta dessa complexidade.

Juridicamente, a terceirização desafia o próprio conceito de empregador, provocando ruptura no binômio empregado-empregador (VIANA, 2006); há um intermediário na relação entre trabalhador e a empresa a quem aproveita a força de trabalho (VIANA, 1998). Ainda juridicamente, pode ser analisada de forma ampla ou restrita, interna ou externa, correspondendo sempre à hipótese em que um terceiro entra na relação de emprego. Em sentido amplo, identifica-se com a tendência empresarial de realizar parte de suas atividades por meio de outras unidades, mais ou menos independentes, incluindo toda a operação - econômica ou de organização da atividade empresarial - de terceirização ou descentralização, qualquer que seja a forma contratual utilizada. Em sentido estrito, como 
mecanismo descentralizador que envolve uma relação trilateral estabelecida entre a empresa que contrata os serviços de outra empresa, terceira, a qual, por seu turno, contrata trabalhadores cujos serviços prestados destinam-se à tomadora. Em sentido interno (VIANA, 2006), expressa a situação em que alguém se coloca entre o empregado e o tomador dos serviços; no sentido externo, evidencia, por exemplo, a situação em que alguém se coloca entre o empresário e o consumidor. No entanto, faces de um mesmo fenômeno, refletem-se da mesma maneira nas relações de poder entre capitalistas e trabalhadores (BALTAR; BIAVASCHI, 2009). 0 presente texto a aborda de forma ampla e nas concepções interna e externa.

Quanto aos institutos da responsabilidade solidária e da subsidiária, tema denso e complexo, interessa reter para este estudo que: na responsabilidade solidária, não acolhida pela Súmula 331, todos os co-devedores são responsáveis pela dívida por inteiro perante o credor comum, cabendo a este, no caso de não pagamento do que lhe é devido, escolher qual o ou os devedores que acionará em Juízo, podendo de qualquer um deles postular, desde logo, o pagamento da integralidade do crédito. 0 co-obrigado que pagou a dívida poderá, depois, buscar ressarcir-se junto aos demais pelo que satisfez além de sua quota parte. Já na responsabilidade subsidiária, o responsável subsidiário será acionado somente quando o devedor principal não tiver comprovadas condições de pagar o que deve. Essa diferença entre os institutos, fundamental, se reflete no maior ou menor tempo de execução do julgado; quando reconhecida a responsabilidade subsidiária da tomadora, a demora é bem maior, como a pesquisa evidenciou.

\section{ENTENDIMENTOS SUMULADOS PELO TST: APRESENTAÇÃO E SIGNIFICADO}

Inicia-se com breve referência a respeito da normatização brasileira sobre terceirização. Não há no País regulamentação específica para essa forma de contratar. 0 que se tem: algumas leis que introduziram a figura da relação trilateral legítima; entendimentos jurisprudenciais incorporados por Súmulas do TST; projetos de lei em andamento no Congresso Nacional; e, propostas de lei elaboradas pela Secretaria de Reforma do Poder Judiciário do Ministério da Justiça, MJ, pelo Ministério do Trabalho e Emprego, MTE, e pela Secretaria de Assuntos Estratégicos, SAE, análise que transborda os limites deste texto.

Em 1974, a Lei 6.019/74, "Lei do Trabalho Temporário", abriu as portas para a terceirização ao introduzir (GONÇALVES, 2004, p. 175) mecanismos 
legais para as empresas enfrentarem a competitividade do sistema econômico globalizado, possibilitando-lhes contratar mão-de-obra qualificada a menor custo e sem responsabilidade direta dos tomadores dessas atividades. Em 1983, a Lei 7.102/83 estendeu para os serviços de vigilância essa contratação atípica. Pela Resolução n.04/86, de 22 de setembro de 1986, o TST introduziu em seus Enunciados o de número 256:

256 - CONTRATO DE PRESTAÇÃO DE SERVIÇOS - LEGALIDADE.

Salvo nos casos de trabalho temporário e de serviços de vigilância, previstos nas Leis ns. 6.019, de 3.1.74 e 7.102, de 20.6.83, é ilegal a contratação de trabalhadores por empresa interposta, formando-se o vínculo empregatício diretamente com o tomador de serviços (BRASIL, 1986).

Esse entendimento, que expressava a jurisprudência àépoca, passou abalizar grande parte das decisões judiciais quer na declaração da existência de vínculo de emprego direto entre o prestador dos serviços e empresa tomadora, beneficiária do trabalho, quer no reconhecimento da responsabilidade solidária das contratantes. Como mostrou a pesquisa, essa situação preponderou no período de 1985-1990, evidenciando a força dos entendimentos sumulados e a dinâmica entre as decisões proferidas nos diversos graus de jurisdição e a construção das Súmulas pelo TST (BALTAR; BIAVASCHI, 2009). Porém, a partir de 1990, em tempos de acirramento da pressão pela flexibilização do mercado de trabalho, a força do movimento pela terceirização da mão-de-obra teve impactos notórios na jurisprudência. A entrevista com o Ministro do TST Renato de Lacerda ilustra essa pressão:

[...] a Lei 6019. De 1974, inclusive a CLT já vem sofrendo algumas alterações importantes, flexibilizando um ponto aqui outro ponto ali e etc. Essa flexibilização realmente precisa ser feita assim mesmo, de modo pontual, gradual. Não pode ser uma reforma profunda porque temos, como disse antes, aquela imensidade de trabalhadores que estão fora do processo. Então, a terceirização é uma necessidade hoje em dia no Brasil, dentro desse processo de flexibilização. Para mim, a questão que se coloca é que a terceirização até há pouco tempo atrás - e digo isso pela minha experiência a partir dos recursos que chegam ao Tribunal Superior do Trabalho - em sua grande maioria não é discutida nos processos, pouco se discute sobre teses jurídicas dentro da terceirização (LACERDA, 2009).

No bojo dessa complexidade, o Enunciado 256 foi revisto: em 1993 e, depois, em 2000, quando aprovada a redação da Súmula 331 que segue: 
331 - CONTRATO DE PRESTAÇÃO DE SERVIÇOS - LEGALIDADE - REVISÃO DO ENUNCIADO N.256.

1 - A contratação de trabalhadores por empresa interposta é ilegal, formandose o vínculo diretamente com o tomador dos serviços, salvo no caso de trabalho temporário (Lei n. 6.019, de 3.1.74).

II - A contratação irregular de trabalhador, através de empresa interposta, não gera vínculo de emprego com os órgãos da Administração Pública Direta, Indireta ou Fundacional (art. 37, II, da Constituição da República).

III - Não forma vínculo de emprego com o tomador a contratação de serviços de vigilância (Lei n. 7.102, de 20.0.83), de conservação e limpeza, bem como a de serviços especializados ligados à atividade-meio do tomador, desde que inexistente a pessoalidade a subordinação direta.

IV - 0 inadimplemento das obrigações trabalhistas, por parte do empregador, implica na responsabilidade subsidiária do tomador dos serviços, quanto àquelas obrigações, inclusive quanto aos órgãos da administração direta, das autarquias, das fundações públicas, das empresas públicas e das sociedades de economia mista, desde que hajam participado da relação processual e constem também do título executivo judicial (artigo 71 da Lei n. 8.666/93) (BRASIL, 2000).

A inclusão, no inciso IV, da responsabilidade subsidiária da Administração direta, Autarquias, Fundações, Empresas Públicas e Sociedades de Economia Mista foi reação ao aprofundamento da terceirização no Poder Público. Em 1997, a Reforma Administrativa (PEC 41/97) ${ }^{7}$, entre outras medidas, a introduziu na Administração Pública direta e indireta ${ }^{8}$.

\section{A AlteraÇÃo do ENTENDIMENTO SUMULADO PELO TST: DINÂMICA E PRESSÕES}

Para a mudança do entendimento sumulado pelo TST quanto à terceirização foi importante o Inquérito Civil Público instaurado pelo Ministério Público do Trabalho, MPT, objetivando investigar denúncia de uso pelo Banco

${ }^{7}$ PEC = Proposta de Emenda à Constituição. As reformas constitucionais tramitam sob a
modalidade de PEC. A Reforma Administrativa, encaminhada pela PEC 41/97, foi instituída
pela Emenda Constitucional (EC) n. 19, de 04/06/1998, que alterou a constituição.
${ }^{8} 0$ contrato de emprego, além de submeter o servidor aos deveres do regime estatutário sem
as vantagens correspondentes (ex: estabilidade, aposentadoria integral), flexibiliza o ingresso. 
do Brasil de mão-de-obra ilegal de digitadores (BALTAR; BIAVASCHI, 2009). Teve atuação destacada nesse processo o então Subprocurador-Geral, hoje Ministro Ives Gandra da Silva Martins Filho (Gandra $\mathrm{F}^{\circ}$ ) que, em entrevista à pesquisa, em 16 de maio de 2008, esclareceu o contexto em que o debate sobre proibir ou não a terceirização chegou à Procuradoria Geral do Ministério Trabalho e ao TST:

[...] na época em que eu estava no Ministério Público, recebi denúncia dos sindicatos dos bancários contra o Banco do Brasil e a Caixa Econômica Federal. No caso do Banco do Brasil, a denúncia era a de que estava terceirizando atividades próprias do banco, atividades bancárias. E, em relação à Caixa Econômica Federal, a de que estava contratando estagiários em nível tal, que, na verdade, tratava-se de substituição de mão-de-obra (MARTINS FILHO, 2008).

A partir dessa denúncia, em 05 de abril de 1993 o MPT, por meio da Procuradoria Geral, expediu Portaria instaurando o ICP contra o BB para apurar se, de fato, contratava digitadores fora das hipóteses legais (trabalho temporário até 03 meses, Lei 6.019/74; e serviços de vigilância, Lei 7.102/83). Após várias audiências em que o Banco apresentou suas justificativas, em 20 de maio de 1993 foi assinado Termo de Compromisso, destacando-se seus dois primeiros itens. No item I, o Banco, em 180 dias, dispensaria a mão-de-obra locada para as tarefas de digitação e lavagem de carros; 0 item II, ao mesmo tempo em que previa abertura de concurso público em 240 dias para as áreas de limpeza, telefonia, ascensorista, copeiro, estiva e gráfica, garantia a possibilidade de o Banco oferecer solução diversa para o caso, desde que de acordo com a legislação. Submetida essa solução excepcional ao MPT este, se concordasse, isentaria o Banco do cumprimento do segundo item. Ainda, previa a possibilidade de manter contratação de mão-deobra temporária pela Lei 6.019/74. Além disso, não seria considerada locação de mão-de-obra ilegal a contratação de manutenção de vasos ornamentais, frete, transporte coletivo, serviços do Centro Cultural, manutenção da Agência Centro São Paulo, preparação de lanche noturno e locação de veículos.

Decorridos três meses, o Banco dirigiu-se ao Subprocurador-Geral apontando dificuldades para cumprir o item I e requerendo dilação do prazo para desligamento dos digitadores para 240 dias, o que foi acolhido. Em 24 de setembro de 1993, invocando o item que permitia apresentar solução diversa àquela do concurso público em 240 dias, o Banco peticionou. Em análise fática e jurídica sobre as conseqüências para o mundo do trabalho da solução ajustada 
(concurso em 240 dias), enfatizou, entre outros aspectos, o risco do desemprego que o cumprimento do Termo poderia gerar. Em face da repercussão dessa petição para a substituição do Enunciado 256 pela Súmula 331, listam-se seus principais argumentos?:

- 0 cumprimento do item II do Termo abarcava um universo de 13.000 trabalhadores (prestadores de serviços);

- Os trabalhadores que se encontravam alocados na prestação dos serviços perderiam seus empregos, por não dispunham de reais condições para prepararem o concurso; A abertura de concurso faria com que profissionais portadores de diploma de nível superior se candidatassem, em situação de vantagem sobre os prestadores dos serviços;

- A perda do emprego para os prestadores de serviços teria grave impacto social, repercutindo no aumento da informalidade e da violência;

- 0 Banco não locava mão-de-obra, apenas celebrara contrato mercantil com empresas que se obrigavam a prestar serviços especializados;

- 0 Decreto - lei no 200/67 pode ser aplicado ao BB por ser sociedade de economia mista, integrando a estrutura da Administração Federal;

- A Constituição Federal garante liberdade de trabalho, ofício ou profissão (BANCO DO BRASIL, 1993).

0 Banco trouxe jurisprudência e Pareceres. 0 da Consultoria Jurídica do Ministério do Trabalho, aprovado por Almir Pazzianotto, posteriormente Ministro do Trabalho e, mais tarde, Ministro do TST, afirmava:

[...] A empresa organizada para explorar atividade de asseio e conservação exerce atividade legítima e legal. Alias, trata-se de atividade prevista pelo $5^{\circ}$ grupo-Turismo e Hospitalidade da Confederação Nacional do Comércio, do quadro a que se refere 0 art. $577 \mathrm{da}$ CLT, com a correspondente categoria profissional. Parece, ademais, óbvio que as empresas dessa natureza somente possam prestar serviços através de contrato, a terceiros, pessoas físicas ou jurídicas, que não desejam exercer determinada atividade com a utilização de empregados próprios. Inconcebível seria que a previsão legal de empresa de asseio e conservação existisse tão-somente para a execução de serviços a si mesma. Por outro lado, fixando-me na controvérsia gerada pela analogia com a empresa de prestação de serviço temporário, analogia que não

\footnotetext{
${ }^{9}$ Os argumentos constam do manuscrito encaminhado ao TST. Disponível no Memorial da Justiça do Trabalho no Rio Grande do Sul.
} 
resiste ao fulcro conceitual do caráter permanente da atividade de asseio e conservação, prevista em lei como antes anotado, certo é, portanto, que as atividades claramente diferenciam-se (PAZZIANOTTO, 1987).

0 Banco resistia à solução do concurso e postulava a suspensão do Termo de Compromisso. Retoma-se a entrevista com Ives Gandra da Silva Martins Filho a respeito do debate em torno da Súmula 256 do TST:

[...] Exigimos o cumprimento da Súmula 256 e, nos termos dessa Súmula, apenas, poderia haver a terceirização de vigilantes e serviços temporários. E quanto às outras atividades, o termo previa o seguinte: ou abrir concurso ou, no prazo definido para o concurso, encontrar outra solução que estivesse de acordo com o ordenamento jurídico. Pois bem. A Súmula 256 somente admitia terceirização nos termos da Lei 6019/74, para trabalho temporário e trabalho de vigilante. Mas também percebíamos que a jurisprudência do TST começava a mudar (MARTINS FILHO, 2008).

O Subprocurador respondeu mediante despacho cuja relevância para a revisão do Enunciado 256 merece que se o transcreva, ainda que parcialmente ${ }^{10}$ :

[...] (4) Resta, pois, analisar, com maior profundidade a questão da autorização legal para o Banco contratar indiretamente pessoal para serviços de apoio. Em relação a tal aspecto, temos que:

(a) a autorização concedida à administração pública para contratar indiretamente os serviços de conservação, transporte e assemelhados diz respeito exclusivamente à administração direta e autárquica, não abrangendo as empresas públicas e sociedades de economia mista;

(b) o inquérito teria desembocado na imposição do reconhecimento do vínculo empregatício direto com o Banco (com o que não estaria o Sindicato adotando qualquer medida judicial, pois os interesses dos trabalhadores teriam sido a integralmente atendidos), não fosse a recente decisão do STF, no sentido de que as sociedades de economia mista também estão sujeitas à regra do concurso público para a contratação de empregado;

(c) o problema do possível desemprego dos trabalhadores das prestadoras de serviço com a não renovação dos contratos e da adequação da clientela ao concurso público, especialmente na área de asseio e conservação, poderia perfeitamente ser resolvido, dentro do que dispõe a Constituição Federal,

${ }^{10}$ Os argumentos constam do manuscrito encaminhado ao TST. Disponível no Memorial da Justiça do Trabalho no Rio Grande do Sul. Acervo "A Terceirização e a Justiça do Trabalho" documentos Ives Gandra da Silva Martins Filho, 1993. 
optando-se por realizar um concurso de provas e títulos, onde a experiência profissional dos trabalhadores que já prestaram serviços no Banco do Brasil poderia ser levada em consideração [...];

(d) resta, no entanto, acaso adotada tal solução, o problema das prestadoras se serviços, que, sustentando a legalidade da atividade que desenvolvem na intermediação permanente de mão-de-obra, deixariam de contar com os contratos que ora têm com o Banco do Brasil [...];

(5) 0 único argumento sólido que justificaria uma revisão da postura adotada pelo MPT presente inquérito seria 0 relativo à dificuldade adicional que a exigência do concurso público trouxe às empresas estatais no campo dos serviços de apoio. Com efeito:

a autorização legal que a administração direta e autárquica têm para contratar indiretamente os serviços de limpeza e assemelhados decorre, naturalmente, da dificuldade prática da adequação da clientela de um concurso público para os serviços de limpeza, pois seria aprovado pessoal com maior qualificação que a necessária, realizando insatisfatória e desmotivadamente os serviços para os quais foi admitido;

as empresas públicas e sociedades de economia mista não estavam abrangidas por tal autorização legal tendo em vista que podiam contratar pessoal sem a necessidade de concurso público;

com a Constituição de 1988 e a interpretação a ela dada pelo Supremo Tribunal federal, verifica-se que as condições fáticas que ensejaram a orientação do art. $3^{\circ}$, § único, da lei 5.645/70 passaram a ser as mesmas enfrentadas pelas empresas estatais, no que concerne à dificuldade de realização de concurso público para serviços de apoio que não requeiram escolaridade ou qualificação especial;

(6) Considerando as dificuldades ora enfrentadas pelo Banco do Brasil quanto à realização do concurso público previsto em termo de compromisso que pôs fim ao inquérito civil público e a impossibilidade do MPT desobrigálo de seu cumprimento enquanto estiver vigente a Súmula n ${ }^{\circ} 256$ do TST com sua redação atual, decidimos fazer uso da faculdade que nos confere 0 art. 83 da Lei Complementar 75/93, pedindo ao TST a revisão do enunciado em tela, para que exclua as empresas estatais da incidência de seus termos.

(7) Enquanto não houver a revisão do enunciado, já requerida ao TST, fica vigente o termo de compromisso [...] (MARTINS FILHO, 1993).

Esse despacho foi assinado em contexto de grande pressão. Em 20 de setembro de 1993, o Subprocurador foi intimado a prestar informações em Mandado de Segurança impetrado pela Federação dos Empregados em Turismo 
e Hospitalidade do Distrito Federal. Seguiram-se dois outros Mandados de Segurança: um, envolvendo Sindicato dos Trabalhadores em Processamentos de Dados e Empregados de Empresas de Processamento de Dados do Estado de São Paulo-SIND/SP; outro, a Federação Brasileira dos Sindicatos e Associações de Empresas de Asseio e Conservação. Retoma-se a entrevista quando aponta os motivos da revisão do Enunciado 256:

[...] as razões que o Banco deu para não realizar concurso em determinadas atividades nos convenceram totalmente. A capilaridade do Banco do Brasil, hoje, é semelhante à capilaridade dos Correios, da Previdência Social. [...] Se eles abrissem concurso para pessoal de limpeza, o que iria acontecer? Dilemas: primeiro, deve-se exigir um mínimo de escolaridade ou não? Segundo, como vai ser a prova se não se exigir escolaridade? Como vai ser a avaliação? Exigindo-se escolaridade mínima, quem vai passar no concurso vai ser quem tem maior conhecimento das matérias que colocadas no concurso, e não a melhor pessoa para realizar aquela atividade? E aquele, desempregado, que estaria feliz fazendo trabalho de limpeza, realizado, não poderia ser selecionado. Enfim, em um Brasil em que os salários são baixos e o desemprego alto, calculava-se a quantidade de gente que se inscreveria para o concurso. [...] Mas se não se optasse pela avaliação da escolaridade, mas buscar ver, realmente, quem seria o melhor em limpeza, como criar algum tipo de padrão de comparação? Quem conseguisse deixar 0 vidro das janelas mais brilhante? Quem conseguisse arrumar melhor a sala? [...] Assim, chegamos à seguinte conclusão: Existem atividades para as quais é impossível a realização de concurso (MARTINS FILHO, 2008).

Em 06 de outubro de 1993 o Subprocurador Geral encaminhou ao TST pedido de revisão do Enunciado 256 sugerindo, ao final, a redação alternativa, como segue:

Enunciado no 256 - CONTRATAÇÃO DE PRESTAÇÃO DE SERVIÇOS LEGALIDADE - Salvo os casos previstos nas Leis no $6.019 / 74$ e 7.102/83, é ilegal a contratação de trabalhadores por empresa interposta, inclusive para serviços de limpeza e digitação, formando-se o vínculo diretamente com 0 tomador de serviço, com exceção das empresas públicas, sociedades de economia mista e órgãos da administração direta, autárquica e fundacional (MARTINS FILHO, 1993).

Ainda segundo Ives Gandra da Silva Martins Filho (2008), na entrevista:

[...] Os ministros, na época, sensibilizaram-se com o problema e a Súmula saiu na última sessão judiciária, na sessão de encerramento do ano judiciário de 1993, no dia 17 de dezembro de 1993. Em que sentido? No sentido da 
espinha dorsal de como nós entendemos a terceirização. A terceirização pode se dar de duas formas: sob a forma de prestação de serviços e sob a forma de intermediação de mão-de-obra. Terceirização sob a forma de prestação de serviços é legítima tanto para atividades-fim quanto para atividadesmeio. [...] Na terceirização sob a forma de intermediação de mão-de-obra o trabalhador é de outra empresa, mas trabalha no local de trabalho da tomadora, com os empregados desta. Nesse caso, a terceirização somente é possivel para as atividades-meio.

0 tema foi para a Comissão de Súmula do TST. Seu Presidente, Ministro Ney Proença Doyle, sublinhou, em parecer, que as Turmas do TST por diversas oportunidades posicionaram-se no sentido da inaplicabilidade do Enunciado 256 à Administração Pública, enfatizando, porém, que a questão não estava pacificada, havendo divergência de entendimentos entre as Seções Especializadas e as Turmas do Tribunal. A entrevista com o Ministro do TST Vantuil Abdala (2009) foi elucidativa:

[...] começaram a aparecer acórdãos abrindo exceções ao que seria 0 entendimento do Enunciado 256, para dizer naquele caso concreto não havia pura e simplesmente intermediação de mão de obra. [...] as novas decisões confrontavam-se com o entendimento do Enunciado 256. Assim, resolvemos fazer outro Enunciado.

As divergências não se limitavam ao setor público. Daí, com o objetivo declarado de unificar a jurisprudência, o Presidente da Comissão propôs revisão do Enunciado 256, apresentando duas opções:

CONTRATO DE PRESTAÇÃO DE SERVIÇOS - LEGALIDADE - REVISÃO DO ENUNCIADO No 256

I - A contratação de trabalhadores por empresa interposta é ilegal, formandose o vínculo diretamente com o tomador dos serviços, salvo no caso de trabalho temporário (Lei n ${ }^{0}$ 6.019, de 03.01.74).

II - A contratação irregular de trabalhador, através de empresa interposta, não gera vínculo do emprego com os órgãos da Administração Pública Direta, Indireta ou Fundacional (Art. 37, II, da C.F.).

$1^{a}$ opção:

III - Não forma vínculo de emprego com o tomador a contratação de serviços de vigilância (Lei 7.102, de 20.06.83), de conservação e limpeza, bem como a de serviços especializados ligados à atividade meio do tomador, desde que inexistente a pessoalidade e a subordinação direta. 


\section{$2^{a}$ opção:}

III - Não configura vínculo de emprego com o tomador a contratação de serviço de vigilância (Lei 7.102, de 20.06.83), de conservação e limpeza, bem com ao de serviços especializados ligados à atividade-meio do tomador, desde que não disponha de empregados próprios nestas funções.

IV - 0 inadimplemento das obrigações trabalhistas, por parte do empregador, implica na responsabilidade subsidiária do tomador dos serviços quanto àquelas obrigações, desde que este tenha participado da relação processual e consta também do título executivo judicial (DOYLE, 1993).

A Comissão de Súmula foi bem além do MPT, ampliando as possibilidades da terceirização. Em 17 de setembro de 1993, a Resolução nº 23/93-0E aprovou 0 texto que passaria a compor a seguinte Súmula de Jurisprudência do TST:

\section{ENUNCIADO N $\mathrm{N}^{0} 331$ - CONTRATO DE PRESTAÇÃO DE SERVIÇOS - LEGALIDADE - REVISÃO DO ENUNCIADO 256 \\ I - A contratação de trabalhadores por empresa interposta é ilegal, formando-} se o vínculo diretamente com o tomador dos serviços, salvo no caso de trabalho temporário (Lei n 6.019, de 03.01.74).

II - A contratação irregular de trabalhador, através de empresa interposta, não gera vínculo do emprego com os órgãos da Administração Pública Direta, Indireta ou Fundacional (Art. 37, II, da Constituição da República).

III - Não forma vínculo de emprego com o tomador a contratação de serviços de vigilância (Lei 7.102, de 20.06.83), de conservação e limpeza, bem como a de serviços especializados ligados à atividade meio do tomador, desde que inexistente a pessoalidade e a subordinação direta.

IV - 0 inadimplemento das obrigações trabalhistas, por parte do empregador, implica na responsabilidade subsidiária do tomador dos serviços quanto àquelas obrigações, desde que este tenha participado da relação processual e consta também do título executivo judicial (BRASIL, 2000).

Ainda que a aprovação da Súmula 331 não tenha sido unânime e conquanto muitas das decisões que a pesquisa examinou não adotassem o entendimento que ela passou a incorporar, o Enunciado 256 foi revisto. A pressão foi enorme, de vários setores. Lembrou Gandra $\mathrm{F}^{0}$ a ação de Sindicatos de trabalhadores, em especial do Sindicato dos Prestadores de Serviço, representante dos contratados para os serviços de digitação e compensação dos cheques (BIAVASCHI, 2007).

Mas na redação da Súmula 331 de 1993 havia lacuna quanto à responsabilidade do Ente Público que contrata terceiras. Para supri-la, o TST, em 
2000, acresceu ao inciso IV a responsabilidade subsidiária da Administração Pública quanto às obrigações trabalhistas. Sobre esse acréscimo, esclareceu Abdala (2009):

[...] cada vez mais a terceirização acontecia no âmbito de entidades públicas, principalmente em estados e municípios, sociedades de economia mista, fundações, empresas públicas. Por incrível que pareça, era onde havia 0 maior numero de inadimplência das prestadoras de serviços, talvez motivado esse fato pela circunstância de que essas prestadoras são contratadas por meio de uma licitação e, pela legislação, deveria ser escolhida a empresa que apresentasse 0 menor preço.

[...] Diante disso, achamos que deveríamos ousar e ir em frente e dizer que havia a responsabilidade da entidade pública, dando uma interpretação nesse sentido ao dispositivo da Lei de Licitação, não dizendo que ele era inconstitucional, mas que não se aplicava a esse tipo de contrato, embora sendo contrato de licitação. Acho que foi uma das coisas mais importantes que esse Tribunal fez, de maior repercussão social, houve uma reação muito grande por parte de vários Ministros, como houve uma reação muito grande no mundo jurídico.

A responsabilidade subsidiária do Ente Público foi comemorada por certos setores sociais. Mas continuou forte a pressão de outras forças para eliminá-la. Recentemente, em 24 de novembro de 2010, Ação Declaratória de Constitucionalidade proposta pelo Governador do Distrito Federal ao artigo 71, $\S 1^{\circ}$ da Lei de Licitações foi julgada procedente pelo STF. 0 dispositivo prevê que a responsabilidade trabalhista das terceiras não se transfere à Administração Pública. Na Ação, um dos argumentos é o de que a interpretação do TST transfere ônus para o Estado, como se este fosse de fato o Segurador Universal da Humanidade, defendendo a terceirização como necessária ao serviço público porquanto: Diminui-se o papel do Estado para que este se torne mais eficiente, mais ágil e menos custoso para a sociedade. Ocorre que esse julgamento acaba por estimular a terceirização no serviço público, podendo impactar futuras decisões sobre o tema.

\section{CONSIDERAÇÕES FINAIS}

0 estudo demonstra que o Judiciário Trabalhista não éum bloco monolítico, sendo constituído a partir de uma arena de disputas. Daí porque o processo de construção das normas e das decisões judiciais não pode ser compreendido apartado das lutas que se dão nas sociedades no momento histórico em que produzidas. Por outro lado, elucida quão complexo é o processo de uniformização 
da jurisprudência pelos Tribunais Superiores e a força que os entendimentos sumulados têm no sentido de balizarem decisões a partir do momento em que construídas. Por outro, ainda, evidenciam que as construções históricas não são lineares, contemplando avanços e retrocessos.

As fontes utilizadas possibilitaram acesso a dados relevantes sobre a construção da Súmula 331, à época um retrocesso em relação ao Enunciado 256 por legitimar a terceirização em certas atividades e adotar a responsabilidade subsidiária da tomadora, contraditada por significativa jurisprudência que ora reconhecia a condição de empregadora da tomadora, ora sua responsabilidade solidária e, em menor densidade, a subsidiária que a Súmula 331 incorporou. Mesmo assim, certas forças sociais ainda a consideram obstáculo a ser eliminado. De qualquer sorte, o estudo trouxe elementos importantes à discussão sobre 0 papel da Justiça do Trabalho diante da terceirização e sobre sua relevância como instância reguladora das relações de trabalho.

\section{REFERÊNCIAS}

ABDALA, Vantuil. Entrevista realizada para subsidiar pesquisa sobre a Terceirização e a Justiça do Trabalho, versando sobre o processo de terceirização na indústria de celulose e papel no Brasil. Porto Alegre: Memorial da Justiça do Trabalho do Rio Grande do Sul, 2009. Entrevista concedida a Magda Barros Biavaschi.

BALTAR, Paulo Eduardo de Andrade; BIAVASCHI, Magda de Barros. Relatório científico final. Campinas: FAPESP, 2009. Disponível em: <ttp://www.revistas. unifacs.br/index.php/redu/article/view/918/669>. Acesso em: 11 dez. 20.10.

BANCO D0 BRASIL. Manuscrito. Brasília, 1993. Documento encaminhado ao Ministério Público do Trabalho. Disponível no Memorial da Justiça do Trabalho no Rio Grande do Sul. Acervo "A Terceirização e a Justiça do Trabalho".

BRASIL. Tribunal Superior do Trabalho. TST no 256. 2000. Disponível em: $<$ http://www.brjuris.com.br/2010/06/sum256-contrato-de-prestao-de-servioslegalidade>. Acesso em: $11 \mathrm{dez} .20 .10$.

BRASIL. Tribunal Superior do Trabalho. TST Enunciado no 331 - Revisão da Súmula no 256. 2000. Disponível em: <http://www.dji.com.br/normas_inferiores/ enunciado_tst/tst_0331a0360.htm>. Acesso em: 11 dez. 20.10.

BIAVASCHI, Magda Barros. 0 direito do trabalho no Brasil: 1930-1942. São Paulo: LTr, 2007. 
FALVO, Josiane Fachini. Balanço da regulamentação da terceirização do trabalho em países selecionados da América Latina. Revista da ABET, Campinas, v. 8, 2010. GONÇALVES, Antônio Fabrício de Matos. Flexibilização trabalhista. Belo Horizonte: Mandamentos, 2004

GRAU, Eros. Ensaio e discurso sobre a interpretação/aplicação do direito. São Paulo: Malheiros, 2002.

KREIN, José Dari. As tendências recentes na relação de emprego no Brasil: 19902005. 2007. Tese (Doutorado de Economia Social e do Trabalho) - UNICAMP, Campinas.

MARTINS FILHO, Ives Gandra da Silva. Entrevista realizada para subsidiar pesquisa sobre a Terceirização e a Justiça do Trabalho, versando sobre o processo de terceirização na indústria de celulose e papel no Brasil. Porto Alegre: Memorial da Justiça do Trabalho do Rio Grande do Sul, 2008. Entrevista concedida a Magda Barros Biavaschi.

MARTINS FILHO, Ives Gandra da Silva. Manuscrito. Brasília, 1993. Documento encaminhado ao Tribunal Superior do Trabalho. Disponível no Memorial da Justiça do Trabalho no Rio Grande do Sul. Acervo "A Terceirização e a Justiça do Trabalho".

NEUMANN, Franz L. Il diritto des lavoro fra democrazia e dittatura. Bologna: Il Mulino, 1983.

PAIVA, Renato de Lacerda. Entrevista realizada para subsidiar pesquisa sobre a Terceirização e a Justiça do Trabalho, versando sobre o processo de terceirização na indústria de celulose e papel no Brasil. Porto Alegre: Memorial da Justiça do Trabalho do Rio Grande do Sul, 2009. Entrevista concedida a Magda Barros Biavaschi.

PAZZIANOTTO, Almir. Manuscrito. Brasília, 1987. Documento encaminhado ao Tribunal Superior do Trabalho. Disponível no Memorial da Justiça do Trabalho no Rio Grande do Sul. Acervo "A Terceirização e a Justiça do Trabalho".

POCHMANN, Márcio. A superterceirização do trabalho. São Paulo: LTr, 2008.

POULANTZAS, Nicos. Estado, o poder, o socialismo. Rio de Janeiro: Graal, 1990.

VIANA, Márcio Túlio. Terceirização e sindicato: um enfoque para além do Direito. 2006, digitado. . 0 novo contrato de trabalho: teoria, prática e crítica da lei n. 9.601/98. São Paulo: LTr, 1998. 